\title{
Impact of COVID-19 on the circulation of respiratory viruses in a children's hospital: an expected absence
}

\author{
M. Florencia Lucion ${ }^{a}$ (D), M. del Valle Juárez ${ }^{a}(\mathbb{D})$, M. Natalia Pejito ${ }^{a}$ (D), \\ Ana S. Orqueda ${ }^{a}(\mathbb{D})$, Lucía Romero Bollón ${ }^{a}$ (D) Alicia S. Mistchenko ${ }^{b}$ (D) \\ Ángela Gentile ${ }^{a}$ (D)
}

\begin{abstract}
Introduction. Respiratory viruses are the main cause of acute lower respiratory tract infection (ALRTI) in the pediatric population. In March 2020, the World Health Organization declared that the new coronavirus disease 2019 (COVID-19) had reached the pandemic status. Our objective was to describe the impact of COVID-19 pandemic on hospitalizations due to ALRTI at Hospital de Niños Ricardo Gutiérrez (HNRG) and virus circulation.
\end{abstract}

Methods. Observational, retrospective, and descriptive study of patients hospitalized due to ALRTI comparing 2019 and 2020.

Results. In 2020, the rate of hospitalization due to ALRTI decreased by $73 \%$. In 2019, 517 patients with ALRTI were hospitalized; the following viruses were identified in 174: respiratory syncytial virus (RSV) $(71.2 \%)$, adenovirus (AV) $(10.3 \%)$, parainfluenza virus (PIV) $(9.7 \%)$, and influenza virus (FLU) (8.6\%). In 2020, 94 patients with ALRTI were hospitalized. Until epidemiological week (EW) 13, cases of ALRTI due to PIV and AV were recorded; in EW 29, there was 1 case of bronchiolitis due to AV and rhinovirus (RV), followed by isolated cases of RV; no ALRTI due to RSV or FLU was recorded. In total, 9 cases of ALRTI due to COVID-19 were recorded: 2 moderate bronchiolitis and 7 focal pneumonia; 1 adolescent with comorbidities died due to COVID-19 pneumonia. In 2020, patients were older and had more comorbidities and prior hospitalizations compared to 2019. Focal pneumonia prevailed.

Conclusion. In 2020, the rate of hospitalization due toALRTIdecreased significantly compared to 2019, with the absence of seasonal respiratory virus circulation in the pediatric population.

Key words: virus, respiratory tract infections, bronchiolitis, COVID-19, epidemiological surveillance.

http: / / dx.doi.org/10.5546/ aap.2022.eng.99

To cite: Lucion MF, Juárez MV, Pejito MN, Orqueda AS, et al. Impact of COVID-19 on the circulation of respiratory viruses in a children's hospital: an expected absence. Arch Argent Pediatr 2022;120(2):99-105.

\section{INTRODUCTION}

Acute respiratory tract infections are the main cause of morbidity and mortality in children younger than 5 years, especially in low- and middleincome countries. ${ }^{1,2}$ Respiratory viruses are the main cause of severe acute respiratory tract infection (ARTI) in the pediatric population. ${ }^{3}$

In March 2020, the World Health Organization declared that the new coronavirus disease 2019 (COVID-19), caused by the severe acute respiratory syndrome coronavirus 2 (SARS-CoV-2) had reached the pandemic status, with a high impact worldwide. More than 1 year after such declaration, 178 million cases have been confirmed and 3.8 million deaths have been reported in over 200 countries. $^{4}$

The pediatric population has been affected by COVID-19 in a different manner than by the 2009 pandemic caused by the H1N1 influenza virus, when children had been greatly impacted, even more than by respiratory syncytial virus (RSV), as the main agent in respiratory infections during the highest circulation period. ${ }^{5}$

Children with SARS-CoV-2 usually have short, mild symptoms, and 15$35 \%$ may be asymptomatic. Most have a documented family contact, who usually develops symptoms before them. ${ }^{6}$

In our country, since the onset of the pandemic until June $12^{\text {th }}, 2021$, more than 400000 cases had been confirmed in individuals younger than 20 years, which account for 10\% of all confirmed cases in Argentina. The median age of confirmed 
cases was 15 years; $2.6 \%$ were younger than 1 year, with no differences between males and females. Most cases were mild and moderate. In $0.2 \%$, intensive care was required; and the case fatality rate was $0.06 \%$. Among deceased patients, $89 \%$ had comorbidities; the most frequent ones were chronic neurological disease and immunosuppression. To date, 161 cases of multisystem inflammatory syndrome and 1 death have been reported. ${ }^{7}$

In order to stop the spread of SARS-CoV-2, in Argentina, 2 policies were implemented initially: preventive and mandatory social isolation and preventive and mandatory social distancing. In addition, on March $15^{\text {th }}, 2020$, inperson classes were suspended nationwide at all levels until October 2020, when school activities aimed at reconnection, guidance, and exchange and in-person activities to end the school year were carried out. Such protocol established the possibility of organizing extracurricular education activities (related to arts, sports, recreation, academic support, etc.) aimed at children, adolescents, and youth with a maximum of 10 participants, preferably outdoors and in compliance with health safety measures established in emergency regulations. ${ }^{8}$

It is known that SARS-CoV-2 is mainly spread through respiratory droplets and aerosol dispersion in settings that are closed, poorly ventilated, and crowded. Other respiratory viruses that may cause an acute lower respiratory tract infection (ALRTI) are spread through droplets and direct or indirect contact with an intermediate object or surface. Based on their similar modes of transmission, it is of special interest to investigate how such measures affected seasonal virus circulation in the population. ${ }^{9,10}$

The objective of this study was to describe the impact of the COVID-19 pandemic on hospitalizations due to ALRTI and the virus circulation pattern at HNRG.

\section{POPULATION AND METHODS}

Study design: Observational, retrospective, and descriptive study of patients hospitalized due to ALRTI comparing 2019 and 2020.

Population: Analyzed data were obtained from the digital database of the ALRTI Epidemiological Surveillance Program of HNRG, which is prospectively completed through active epidemiological surveillance. Data are collected from interviews, case histories, and medical records of patients hospitalized at the clinical hospitalization ward and the intensive care unit of HNRG, who received follow-up since their admission until their discharge. HNRG is a national children's referral hospital that has conducted active epidemiological surveillance of respiratory viruses in patients hospitalized due to ALRTI since 2000. At the onset of the pandemic, HNRG became a referral facility for COVID-19 cases, although it continued caring for patients with other conditions.

Inclusion criteria: Data of all patients hospitalized due to ALRTI during 2019-2020 were included. Hospitalization criteria for ALRTI cases were the same in both periods.

Exclusion criteria: Data of patients hospitalized for a reason other than an ALRTI who developed an ALRTI 48 hours after admission were excluded.

Clinical case definitions: The term ALRTI ${ }^{11}$ includes:

1. Bronchiolitis: first wheezing event associated with clinical evidence of viral infection in children younger than 2 years.

2. Pneumonia: acute infection of the lung parenchyma with clinical signs of invasion of the alveolar space.

Diagnostic method: Before the COVID-19 pandemic, viral diagnosis was done by indirect immunofluorescence (IIF) using monoclonal antibodies in nasopharyngeal aspirates obtained in the first 24 hours of admission. As of 2020, and in the presence of symptoms that met the definition of suspected COVID-19 case, SARSCov-2 was initially ruled out or confirmed by molecular testing, including polymerase chain reaction (PCR) in nasal and/ or pharyngeal swabs. According to the national recommendations, if these tests are negative, the remaining respiratory viruses are tested: RSV, parainfluenza virus (PIV), influenza virus (FLU), adenovirus (AV), and rhinovirus (RV).

Sample size and selection: Data recorded during 2019 and 2020 were collected in a retrospective manner. Cases were included by consecutive sampling over the 2-year study period, and the data of the total study universe were collected.

Data collection: The following data were collected in the epidemiological card: demographic data, clinical presentation, prior hospitalizations, comorbidities, complications during hospitalization, course, treatment, and hospitalization duration.

Statistical analysis: Initially, a general description was done and the mean and standard 
deviation or median and interquartile range (IQR) were estimated for numerical variables based on their distribution, and proportions for categorical variables. Then, a univariate analysis was done to compare clinical and epidemiological variables of ALRTI cases between 2019 and 2020. The odds ratio $(\mathrm{OR})$ with a $95 \%$ confidence interval $(\mathrm{CI})$ was used as a measure of association.

The rates of hospitalization due to ALRTI (per 10000 discharges) were compared between 2019 and 2020. The Epi Info $7^{\circledR}$ software was used for statistical analysis and the OpenEpi ${ }^{\circledR}$ software, for rate comparison.

Ethical considerations: The study was approved by the Ethics and Research Committee of HNRG. This study complied with the research-related regulations established in the Autonomous City of Buenos Aires. The patient informed consent form was not applicable in this study because data were collected from epidemiological surveillance in the setting of Argentine Law no. 15465/60.

\section{RESULTS}

\section{Hospitalization due to ALRTI at HNRG}

In 2019, the rate of hospitalization due to ALRTI was 575.1/10 000 discharges, whereas in 2020, it was 155.3/ 10000 discharges, which meant a significant decrease by $73 \%$ (95\% CI: $-66.3 \%$ $-78.3 \%$ ) during the year of the pandemic.

In 2019, ALRTI cases showed a seasonal epidemic pattern with a peak in the winter months, typical of temperate regions. In 2020, cases were recorded sporadically throughout the year (Figure 1).

\section{Respiratory virus circulation}

During 2019, out of 517 ALRTI cases, 477 were tested (92\%); of these, a virus was identified in 174 $(36.4 \%)$. RSV was the most frequent agent $(71.2 \%)$, followed by AV (10.3\%), PIV (9.7\%), and FLU $(8.6 \%)$. RSV showed the usual winter seasonal pattern with a peak circulation during EW 23, corresponding to early June (Figure 2).

In 2020, 94 ALRTI cases were recorded; 81 $(86.2 \%)$ were tested for respiratory viruses and $32(39 \%)$ were positive. RV was the prevailing agent $(\mathrm{n}=12)$, followed by SARS-CoV-2 $(\mathrm{n}=9)$, $\operatorname{AV}(\mathrm{n}=7)$, and PIV $(\mathrm{n}=4) ; 3$ cases corresponded to co-infections: $2 \mathrm{RV}$ plus $\mathrm{AV}$ and $1 \mathrm{RV}$ plus PIV. In relation to seasonality during 2020, until EW 13 (initiation of preventive and mandatory social isolation policy), some cases of ALRTI due to PIV and AV were recorded; during EW 29, 1 case of bronchiolitis due to AV and RV and isolated cases of RV were identified (Figure 3). No ALRTI cases due to RSV or FLU were recorded. COVID-19 cases prevailed in July through October, consistent with the peak community circulation.

ALRTIs accounted for $2.6 \%(n=9)$ of total COVID-19 cases: 2 cases of moderate bronchiolitis and 7 of focal pneumonia; 1 adolescent with comorbidities (chronic kidney failure and kidney transplant) died due to COVID-19 pneumonia.

\section{Characteristics of the population}

Patients with ALRTI hospitalized in 2020 showed some significant differences compared to those hospitalized in 2019: they were older, had more comorbidities, and prior hospitalizations

FIgURE 1. Distribution of cases of acute lower respiratory tract infection hospitalized at Hospital de Niños Ricardo Gutiérrez during 2019 and 2020

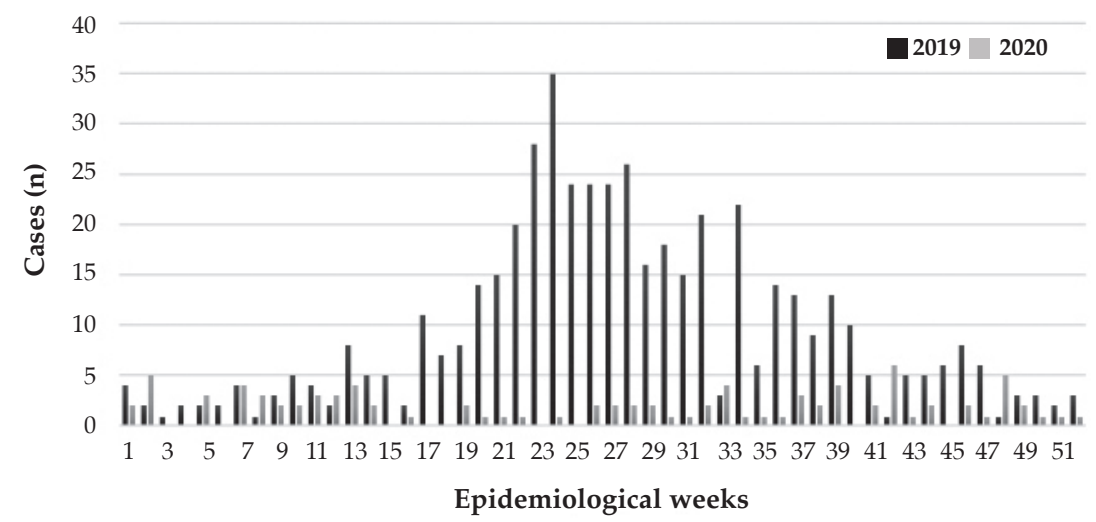


due to respiratory causes. In addition, pneumonia was the prevalent clinical presentation during 2020; whereas in 2019, bronchiolitis was the most frequent condition. No statistically significant differences were noted in terms of sex, severity or fatality rate. During 2020, 2 deaths were recorded among hospitalized patients with ALRTI: SARSCoV-2 was identified in 1 but no virus was isolated in the other (Table 1).

\section{DISCUSSION}

The COVID-19 pandemic had a major impact on the circulation of respiratory viruses worldwide, with a lower incidence of severe ARTIs in most countries. The influenza virus remained below expected levels in all regions globally. In the temperate regions of the Northern Hemisphere, the influenza virus activity was low even between seasons. In Equatorial Africa and South Asia, influenza detection was sporadic or even null in some countries. In such setting of low virus circulation, seasonal influenza A (H3N2) accounted for most detected cases. ${ }^{12}$

In the Southern Hemisphere, the pandemic arrived when the FLU and RSV season was expected to begin. In Oceania, these viruses were almost completely absent during the latest winter season, as shown by the surveillance data for Australia and New Zealand, with a historically low circulation of influenza virus. ${ }^{13,14}$ Australian investigators found a reduction of $98 \%$ and 99.4\% in RSV and FLU detection, respectively,

FIGURE 2. Distribution of cases of acute lower respiratory tract infection hospitalized at Hospital de Niños Ricardo Gutiérrez by viral rescue, 2019

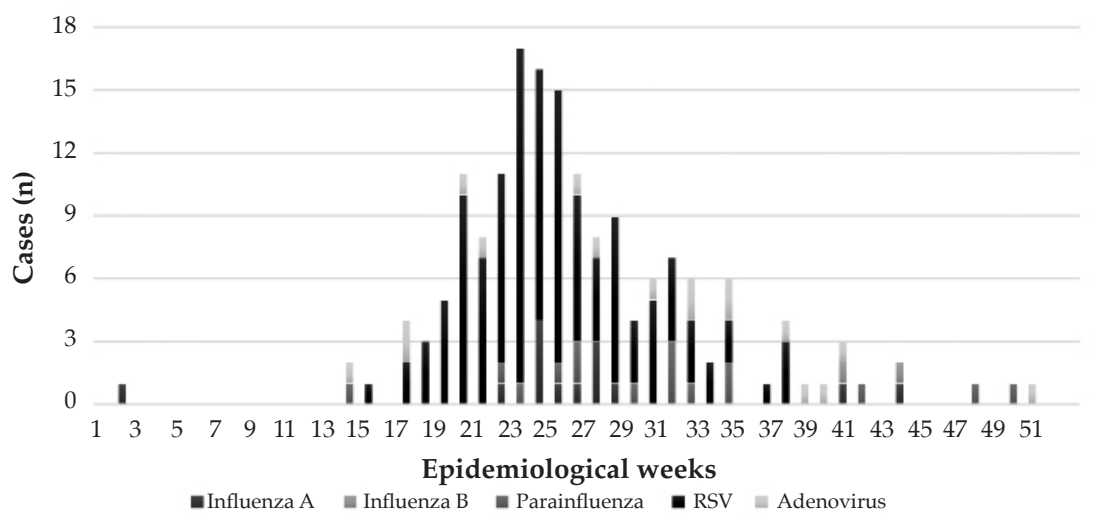

RSV: respiratory syncytial virus.

FIGURE 3. Distribution of cases of acute lower respiratory tract infection hospitalized at Hospital de Niños Ricardo Gutiérrez by viral rescue, 2020

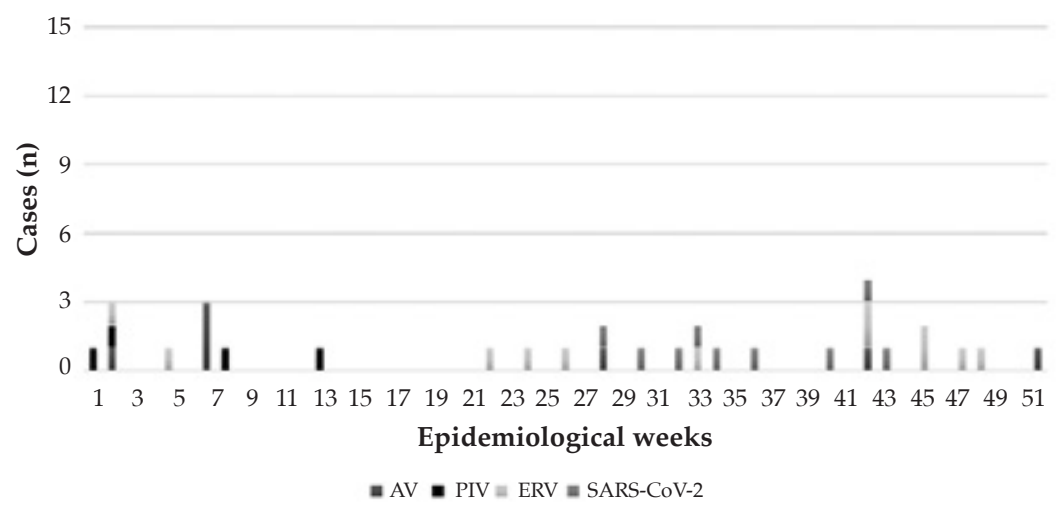

AV: adenovirus, PIV: parainfluenza virus, ERV: entero- and rhinovirus, SARS-CoV-2: severe acute respiratory syndrome coronavirus 2 . 
in children from Western Australia during the 2020 winter, which remained consistent in spite of schools reopening. ${ }^{15}$

In South America, the activity of respiratory viruses was also low, except for SARS-CoV-2, which remained in moderate to high level across the region. ${ }^{12,16}$

Active surveillance of ALRTIs is a critical tool for the rapid detection of any increase in the number of cases, the identification of high risk groups, and the determination of frequency, distribution, and characteristics of disease causing microorganisms. ${ }^{8}$ Viruses are most commonly implied in the acute infection of the lower respiratory tract in children younger than 5 years; the most frequent viruses are RSV, FLU A and B, $\mathrm{AV}$, and PIV 1, 2, and 3; more recently, other pathogens, such as human metapneumovirus and $\mathrm{RV}$, have been recognized as causing ALRTIs and respiratory exacerbations. ${ }^{1-3}$

In Argentina, during 2020, clinical reports of influenza-like illness, bronchiolitis in children younger than 2 years, and pneumonia were way below what was expected compared to the same period in previous years. ${ }^{17}$

During 2020, the rate of hospitalization due to ALRTI at HNRG reduced significantly compared to the previous year, including the lowest number of hospitalizations for any cause, which was also observed in different regions worldwide. ${ }^{18-20}$

ALRTI cases recorded in the setting of epidemiological surveillance show that, before the pandemic, RSV was the most common virus, with a higher incidence among infants younger than 1 year. These results are similar to other epidemiological studies conducted in the region. ${ }^{21-23}$ In addition, RSV circulation in 2019 exhibited a seasonal epidemic pattern, usual in temperate regions, which is consistent with the months of lower mean temperature and higher relative humidity (May-July).24,25

Before the pandemic, FLU was the second most common virus, with incidence peaks in the winter and autumn months, thus exhibiting a seasonal epidemic pattern. In our case series, FLU affected mostly children older than 6 months in whom pneumonia was the clinical presentation and those with a history of prior hospitalizations due to respiratory causes and certain comorbidities. ${ }^{26}$

Unlike RSV and FLU, AV was the only virus circulating during 2020 with similar characteristics to previous years, but with a very low incidence. AV usually circulates all year round, as described in other studies, with incidence peaks in the winter that are consistent with the increase in the number of ALRTI cases. . $^{27,28}$

At HNRG, during 2020, in addition to a completely atypical virus circulation pattern, characterized by the absence of RSV and FLU cases, isolated ALRTI cases due to RV, AV, and PIV, it was observed that hospitalized patients with ALRTI were older and had more comorbidities and a history of prior hospitalization due to a respiratory cause. The latter may be related to the typical characteristics of a population attending a tertiary care children's hospital. In addition, the most common clinical presentation during 2020 was pneumonia, unlike previous years when bronchiolitis, mostly caused

TABLE 1. Comparison of clinical and epidemiological characteristics of ALRTI cases hospitalized at HNRG during 2019 and 2020

\begin{tabular}{lccc}
\hline Characteristics & $\mathbf{2 0 1 9}(\mathbf{n}=\mathbf{5 1 7})$ & $\mathbf{2 0 2 0}(\mathbf{n}=\mathbf{9 4})$ & $p$ value \\
\hline Age in months (median, IQR) & $10(5-21)$ & $16(10-48)$ & $<0.001$ \\
Male sex & $318(61.5 \%)$ & $61(65 \%)$ & 0.56 \\
Prior hospitalization due to respiratory causes & $236(45.6 \%)$ & $54(57.4 \%)$ & 0.036 \\
Comorbidities (total) & $300(58 \%)$ & $73(77.7 \%)$ & $<0.001$ \\
Chronic respiratory disease & $239(79.6 \%)$ & $54(74 \%)$ & 0.29 \\
Clinical presentation & & $39(41.5 \%)$ & $<0.001$ \\
$\quad$ Bronchiolitis & $312(60.3 \%)$ & $55(58.5 \%)$ & $<0.001$ \\
$\quad$ Focal or multifocal pneumonia & $205(39.7 \%)$ & $10(10.6 \%)$ & 0.70 \\
AMV requirement & $48(9.2 \%)$ & $2(2.12 \%)$ & 0.46 \\
Fatality rate & $6(1.16 \%)$ & &
\end{tabular}

ALRTI: acute lower respiratory tract infection, HNRG: Hospital de Niños Ricardo Gutiérrez, IQR: interquartile range, AMV: assisted mechanical ventilation. 
by RSV, was the prevailing clinical presentation.

This study was carried out based on robust, good quality data obtained prospectively; a limitation worth noting is that since this was a hospital-based study, results cannot be extrapolated to the general population. In addition, in 2020, PCR was used for viral etiologic diagnosis (IIF was used before), which allowed to diagnose RV and co-infections that had not been recorded in previous years.

SARS-CoV-2 behavior is expected to change over time because ribonucleic acid viruses mutate easily. Although SARS-CoV-2 has certain "mechanisms to correct" changes in its broad genome made up of 30000 nucleotides, such mechanisms have not prevented mutations caused by some errors resulting from replication. Any variant that may randomly show adaptive advantages may become established, spread, and sometimes turn into the prevailing SARS-CoV-2 variant through a natural selection process. ${ }^{29}$

In relation to preventive measures, close social contact may increase the risk for transmission from an infected person to other susceptible individuals. Therefore, maintaining social distancing, wearing masks, and hand hygiene are measures that have demonstrated to be sufficient and effective to reduce the spread of both SARS$\mathrm{CoV}-2$ and other respiratory viruses.

Mandatory social isolation accompanied with restrictions on public transportation and intensified hygiene measures may be the main cause of such low severe ARTI incidence. Most likely, the preventive measures implemented during the COVID-19 pandemic played a major role in the change of transmission patterns for all respiratory viruses, and the role SARS-COV-2 will play in the behavior of FLU and other respiratory viruses in the following seasons is yet to be determined.

\section{CONCLUSIONS}

The rate of hospitalization due to ALRTI during 2020 decreased significantly compared to the previous season at HNRG. In addition, the usual seasonal respiratory virus circulation was absent in the pediatric population seen at our hospital.

\section{REFERENCES}

1. Nair H, Simoes EA, Rudan I, Gessner BD, et al. Global and regional burden of hospital admissions for severe acute lower respiratory infections in young children in 2010: a systematic analysis. Lancet. 2013; 381(9875):1380-90.

2. Liu L, Johnson HL, Cousens S, Perin J, et al. Global, regional, and national causes of child mortality: An updated systematic analysis for 2010 with time trends since 2000. Lancet. 2012; 379(9832):2151-61.

3. Viegas M, Barrero PR, Maffey AF, Mistchenko AS. Respiratory viruses seasonality in children under five years of age in Buenos Aires, Argentina: a five-year analysis. J Infect. 2004; 49(3):222-8.

4. World Health Organization. WHO Coronavirus (COVID-19) Dashboard. [Accessed on: June 23 ${ }^{\text {rd }}, 2021$ ]. Available at: https: / / covid19.who.int/

5. Gentile A, Bakir J, Russ C, Rubinsky S, et al. Estudio de las enfermedades respiratorias por virus Influenza A H1N1 (pH1N1) en niños internados durante el año de la pandemia. Experiencia de 34 centros en la Argentina. Arch Argent Pediatr. 2011; 109(3):198-203.

6. Alsohime F, Temsah MH, Al-Nemri AM, Somily AM, Al-Subaie S. COVID-19 infection prevalence in pediatric population: Etiology, clinical presentation, and outcome. J Infect Public Health. 2020; 13(12):1791-6.

7. Argentina. Ministerio de Salud. Nuevo Coronavirus 2019. Informes especiales: Niñez, Adolescencia y COVID-19/14-06-2021-SE23. [Accessed on:June 23 ${ }^{\text {rd }}$,2021]. Availableat:https: / / www.argentina.gob.ar/coronavirus / informes-diarios / sala-de-situacion/informes-especiales

8. Decreto 67/2021. DECNU-2021-67-APN. Distanciamiento social, preventivo y obligatorio y Aislamiento social, preventivo y obligatorio. Buenos Aires, Argentina. 29 de enero de 2021. [Accessed on: June 23 ${ }^{\text {rd }}$, 2021]. Available at: https: / / www.boletinoficial.gob.ar/detalleAviso / primera/240233/20210130

9. World Health Organization. Influenza update $\mathrm{N}^{\circ} 390$. [Accessed on: April $\left.7^{\text {th }}, 2021\right]$. Available at: https: / / www. who.int/publications/m/item/influenza-update-n-390

10. Scientific Brief: SARS-CoV-2 and Potential Airborne Transmission. Última actualización: 5 de oct 2020. [Accessed on: April $\left.7^{\text {th }}, 2021\right]$. Available at: https: / / acacimesfe.org/ wp-content/uploads / 2020/10/Scientific-Brief.-SARSCoV-2-and-Potential-Airborne-Transmission.pdf

11. Argentina. Ministerio de Salud del GCBA. Gerencia Operativa de Epidemiología.Subsecretaría de Planificación Sanitaria. Actualización en vigilancia de infecciones respiratorias agudas 2019. [Accessed on: March $8^{\text {th }}, 2021$ ]. Available at: https: / / www.buenosaires.gob.ar/sites / gcaba/files/memo_ira_actualizacion_ano_2019.pdf

12. Organización Panamericana de la Salud. Informe de situación de Influenza SE41 de 2020. Actualización Regional: Influenza y Otros virus respiratorios. Octubre 2020. [Accessed on: May 30 $\left.{ }^{\text {th }}, 2021\right]$. Available at: https: / / www.paho.org/es/informe-situacion-influenza

13. Van Brusselen D, De Troeyer K, Ter Haar E, Vander Auwera A, et al. Bronchiolitis in COVID-19 times: a nearly absent disease? Eur J Pediatr. 2021; 180(6):1969-73.

14. Hills T, Kearns N, Kearns C, Beasley R. Influenza control during the COVID-19 pandemic. Lancet. 2020; 396(10263):1633-4.

15. Yeoh DK, Foley DA, Minney-Smith CA, Martin AC, et al. The impact of COVID-19 public health measures on detections of influenza and respiratory syncytial virus in children during the 2020 Australian winter. Clin Infect Dis. 2020:ciaa1475.

16. Olsen SJ, Azziz-Baumgartner E, Budd AP, Brammer L, et al. Decreased Influenza Activity During the COVID-19 Pandemic-United States, Australia, Chile, and South Africa, 2020. MMWR Morb Mortal Wkly Rep. 2020; 69(37):1305-9.

17. Argentina. Ministerio de Salud. Boletín integrado de vigilancia N518 SE42 - 30/11/2020. [Accessed on: April $7^{\text {th }}$, 2021]. Available at: https: / / bancos.salud.gob.ar/ recurso/ boletin-integrado-de-vigilancia-n518-se42-30112020 
18. PolcwiartekLB, Polcwiartek C, Andersen MP, Østergaard L, etal. Consequences of coronavirus disease-2019(COVID-19) lockdown on infection-related hospitalizations among the pediatric population in Denmark. Eur J Pediatr. 2021; 180(6):1955-63.

19. Curatola A, Lazzareschi I, Bersani G, Covino M, etal. Impact of COVID-19 outbreak in acute bronchiolitis: Lesson from a tertiary Italian Emergency Department. Pediatr Pulmonol. 2021; First published: May 7.

20. Ferrero F, Ossorio MF. Is there a place for bronchiolitis in the COVID-19 era? Lack of hospitalizations due to common respiratory viruses during the 2020 winter. Pediatr Pulmonol. 2021; 56(7):2372-3.

21. Gentile A, Lucion MF, Juarez MV, Areso MS, et al. Burden of Respiratory Syncytial Virus Disease and Mortality Risk Factors in Argentina: 18 Years of Active Surveillance in a Children's Hospital. Pediatr Infect Dis J. 2019; 38(6):589-94.

22. Piñeros JG, Baquero H, Bastidas J, García J, et al. Respiratory syncytial virus infection as a cause of hospitalization in population under 1 year in Colombia. J Pediatr (Rio J). 2013; 89(6):544-8

23. Gamiño-Arroyo AE, Moreno-Espinosa S, LlamosasGallardo B, Ortíz-Hernández A, et al. Epidemiology and clinical characteristics of respiratory syncytial virus infections among children and adults in Mexico. Influenza Other Respir Viruses. 2017; 11(1):48-56.

24. Gurgel RQ, Bezerra PG, Duarte Mdo C, Moura AA, et al. Relative frequency, Possible Risk Factors, Viral Codetection
Rates, and Seasonality of Respiratory Syncytial Virus Among Children With Lower Respiratory Tract Infection in Northeastern Brazil.Medicine (Baltimore). 2016;95(15):e3090.

25. Lución MF, Juárez MV, Viegas M, Castellano V, et al. Virus respiratorio sincicial: patrón clínico epidemiológico en niños internados en un hospital pediátrico durante los años 2000-2013. Arch Argent Pediatr. 2014; 112(5):397-404.

26. Gentile A, Lucion MF, Juárez MV, Martínez AC, et al. Influenza virus: 16 years' experience of clinical epidemiologic patterns and associated infection factors in hospitalized children in Argentina. PLoS One. 2018; 13(3):e0195135

27. BakirJ,JuárezMV,LuciónMF, AresoMS, etal.Estudioclínicoepidemiológico de las infecciones respiratorias agudas bajas causadas poradenovirusenniñoshospitalizados. Diecinueve años de vigilancia epidemiológica activa. Arch Argent Pediatr. 2020; 118(3):193-201.

28. Flomenberg P, Kojaoghlanian T. Pathogenesis, epidemiology, and clinical manifestations of adenovirus infection. UpToDate. [Accessed on: April 30 $0^{\text {th }}, 2021$ ]. Available at: https://www.uptodate.com/contents / pathogenesis-epidemiology-and-clinical-manifestationsof-adenovirus-infection

29. Roy C, Mandal SM, Mondal SK, Mukherjee S, et al. Trends of mutation accumulation across global SARS-CoV-2 genomes: Implications for the evolution of the novel coronavirus. Genomics. 2020; 112(6):5331-42. 